\title{
Medical Waste Management Practices in a Southern African Hospital
}

\author{
PATIENCE ASEWEH ABOR \\ Department of Environmental and Occupational Health, Faculty of Applied Sciences, \\ Cape Peninsula University of Technology, South Africa
}

\begin{abstract}
This study examined the medical waste management practices of a hospital in Southern Africa. The results revealed that the hospital does not quantify medical waste. Segregation of medical wastes into infectious medical waste and non-infectious medical waste is not conducted according to definite rules and standards. Separation of medical waste and municipal waste is however practiced to a satisfactory extent. Wheeled trolleys are used for on-site transportation of waste from the points of production to the temporary storage area. Staff responsible for collecting medical waste use almost completes personal protective equipment. Offsite transportation of the hospital waste is undertaken by a private waste management company. Small pickups are mainly used to transport waste daily to an off-site area for treatment and disposal. The main treatment method used in the final disposal of infectious waste is incineration. Noninfectious waste is disposed off using land disposal method. The study showed that the hospital does not have a policy and plan in place for managing medical waste. There are a number of problems the hospital faces in terms of medical waste management, including; lack of necessary rules, regulations and instructions on the different aspects of collections and disposal of waste, failure to quantify the waste generated in reliable records, lack of use of coloured bags by limiting the bags to only one colour for all waste, the absence of a dedicated waste manager, and no committee responsible for monitoring the management of medical waste. Recommendations are given with the aim of improving medical waste management in hospitals. @JASEM
\end{abstract}

Medical wastes are defined to include all types of wastes produced by health facilities such as general hospitals, medical centres and dispensaries. Medical wastes represent a small amount of total residues generated in a community. However, such residues can potentially transmit diseases and present an additional risk to the staff of the healthcare facilities, patients and the community when the wastes are not managed properly (Baveja, et al, 2000; Silva, 2005). Improper disposal of medical waste including open dumping and uncontrolled burning for instance increases the risk of spreading infections and of exposure to toxic emissions from incomplete combustions.

Medical waste management has become a critical issue as it poses potential health risks and damage to the environment, which has taken a central place in the national health policies of many countries. In developing countries, medical wastes have not received sufficient attention. This is because, very often, health issues compete for the very limited resources. In many countries, hazardous and medical wastes are still handled and disposed together with domestic wastes, thus creating a great health risk to municipal workers, the public and the environment. Medical waste must be separated from municipal waste, but in many parts of Africa it tends to be collected along with the rest of the waste stream (Kgathi and Bolanee, 2001; Taru, 2005). Most hazardous and toxic wastes are placed on land sites with few safeguards to protect those living nearby and water sources from contamination (Hardoy, 1992). A number of empirical studies have therefore attempted to examine the medical waste management practices in a number of hospitals (see Askarian et al, 2004; Rao et al, 2004; Patil and Pokhrel, 2005; Silva et al, 2005; Taru and Kuvarega, 2005). This current study also looked at the medical waste management practices in a Southern African hospital.

In Southern Africa, for instance, medical waste is seen as a mounting problem. In recent times, there have been numerous press statements of medical waste being disposed of in an incorrect manner. This situation has adversely affected the poor disadvantaged members of society. The incineration of medical waste has also caused much concern. Some studies (see Groundwork, 2002), have pointed out that incinerators have been associated with a wide variety of health problems in Southern Africa, such as disrupting the bodies hormonal, immune and reproductive systems, and have caused cancers. It is estimated that about $45 \%$ of health care waste generated in the province of KwaZulu-Natal in South Africa alone, for instance cannot be accounted for, indicating that it is being illegally dumped, buried or bunt somewhere, thus affecting the health of the people and the environment (Leonard, 2004). There is often the lack the capacity to properly dispose of huge amounts of medical waste being generated. There have been numerous instances where medical wastes have been dumped in residential areas, thus posing serious health risk to the community and environment. The illegal dumping of medical wastes in disadvantaged residential areas has resulted in situations where children have been found playing with medical waste materials such as syringes. For example, a hospital in South Africa treated 48 children with AZT after some were pricked with needles and others ate potentially lethal pills they found in a field in Elsie's River (Cape Argus, September 1999). 
In the light of all the above, this study sought to examine the medical waste management practices in one major hospital in Southern Africa. For the case of confidentiality, the hospital would be referred to as Kotuba Hospital. This current study empirically examined the medical waste management practices of Kotuba Hospital. The rest of the paper is organized as follows: the next section explains the methodology employed for the study. Section three includes the results and discussion. The conclusion and recommendations are covered in section four.

\section{Research Design and Methodology}

This study is a case study of a hospital in Southern Africa. The hospital used in this research is a Southern African hospital, which for the sake of confidentiality would be referred to as Kotuba Hospital. The Kotuba hospital is located one of the oldest, largest, most advanced, and comprehensive medical compounds in Southern Africa. Therefore, it is expected that the level of awareness of the importance of the proper handling of medical waste will be higher than other hospitals in the sub region. As a teaching hospital, Kotuba hospital comprises of many departments such as the wards, the casualty, the minor operating theatre, the major operating theatre, a maternity section, the laboratory, X-ray section etc.

The methodology to be adopted for this study follows that used by Oweis et al (2005). This includes a twostage strategy:

1. Examining the rules, procedures, and regulations set forth by the hospital's directory to be followed by the personnel regarding the management of medical waste generated at the hospital.

2. Spending enough time in the different departments of the hospital recording observations and writing notes in the critical manner about the practices of the medical waste management by staff responsible for waste management.

The researcher made frequent visits to the hospital, taking note of how medical waste is managed. Regular visits were made to general medical wards, maternity wards, surgical and critical care wards, operating theatres, and orthopaedic sections. Also, based on the recommendations of the World Health Organisation for evaluation of hospital waste management in developing countries, (Prüss et al., 1999, WHO, 2001) a data form and questionnaire were developed. After taking into consideration specific Southern African differences and the views of the environmental health specialists regarding the present problems in the management of medical waste and the expected results from the questionnaire, some modifications were made to the questionnaire suggested by the WHO. The site visits were very helpful in obtaining information about the common practices in the management of the wastes.

The results obtained were discussed to ascertain the extent to which the medical wastes are handled in the light of written policies and the established international standards in this regard (WHO, 1999). This is purely a case study and analysis is essentially descriptive. Data for the analysis was extracted from questionnaire and personal interviews carried out by the researcher.

\section{RESULTS AND DISCUSSION}

This section includes the results and discussion of the study. It begins by providing a profile of the Kotuba Hospital used in this study.

Profile of Kotuba Hospital: Kotuba hospital, which is the leading health facility in it municipality for trauma and other acute cases, was built during the time of apartheid. It was officially opened in 1976. Originally one half of the hospital housed "white patients" and the other half "non-whites". Since 1994, and with the end of the apartheid regime, large parts of the hospital's building have been left idle. The vast majority of patients using this state facility are "non-whites", with only a handful of "white patients" attending for specialists' outpatient services. Most wealthy people attend private hospitals. The hospital was designed for 1,899 beds, but presently has 1,278 active beds, including 300 beds for its Children's hospital, Day surgery unit and Private patients units. The hospital has about 50 wards, 28 theatres and 30 out patient departments.

Kotuba hospital, which serve as the teaching hospital for a university has a staff strength of about 4,000 has as its mission the provision of affordable world class quality health care to public and private patients within available resources, as well as excellent educational and research opportunities. The hospital caters for all specialities appropriate to a large academic hospital, as General Surgery and subdisciplines, e.g. orthopaedics, ophthalmology, etc, Internal Medicine and sub-disciplines, e.g. cardiology and nephrology, as well as Obstetrics and Gynaecology. Over 2 million people receive health care from Kotuba hospital either directly or through its secondary hospitals.

Kotuba hospital plays a central role in the delivery of Tertiary services and Secondary services in its municipality. The hospital makes significant 
contribution to teaching and training of health professionals as well as research in partnership primarily with the some universities in Southern Africa.

Medical Waste Management Practices

Waste Production: Waste is generated from the various activities performed in the hospital. Wastes produced in the hospital include general and medical wastes. General waste produced at the hospital is related to food preparation, administrative departments, and landscaping. This type of waste is similar to household and city wastes. In the Kotuba hospital, different kinds of therapeutic procedures such as cobalt therapy, chemotherapy, dialysis, surgery, delivery, resection of gangrenous organs, autopsy, biopsy, para-clinical exams, injections, etc., are carried out and result in the production of infectious wastes, contaminated sharps with patients' blood and secretions, radioactive wastes and chemical materials which are considered to be hazardous wastes (Prüss et al., 1999). The amount of waste generated in hospitals depends upon various factors such as number of beds, types of health services provided, economic, social and cultural status of the patients and the general condition of the area where the hospital is situated. For example, in hospitals located in low socioeconomic areas of the cities, most of the waste consists of residues from fruits which are voluminous and abundant, whereas in those located in high socioeconomic areas of the city; most of wastes contain flowers, cans and single use containers for food (Askarian et al, 2004). However, during our interview with waste management staff in the hospital, they could not tell the amount of waste generated in the hospital daily. They could not also provide information with respect to which departments generate the highest and lowest amounts of medical waste in the hospital.

Waste Segregation: The hospital basically separates medical waste from general waste stream at the waste production points. Therefore they are stored and disposed off separately. However, the hospital does not segregate medical wastes into different categories. In the wards, doctors and nurses who use sharps are required to drop them into different containers but this is not diligently followed. Users of sharps sometimes leave them on hospital beds and this could be very dangerous to patients. According to the proposal by $\mathrm{WHO}$, hospitals have to provide plastic bags and strong plastic containers for infectious waste such as empty containers of antiseptics used in the hospital. Bags and containers for infectious waste should be marked with Biohazard symbol (Prüss et al., 1999). During our interview it was revealed that segregation of medical wastes into infectious medical waste and noninfectious medical waste is not conducted according to definite rules and standards. The hospital does not label infectious waste with Biohazard symbol. No control measures exist for the management of these wastes. Separation of medical waste and general waste is however practiced to a satisfactory extent.

On-site Transport of Medical Waste: Medical wastes generated in the hospital are on a daily basis collected and transported to a temporary storage area by hospital's staff. It is imperative for medical waste to be transported within the hospital by means of wheeled trolleys, containers or carts that are not used for any other purpose. In Kotuba hospital wheeled trolleys are used for on-site transport of waste from the sites of production (different wards) to the temporary storage area. The staff employed for handling waste in the hospital use almost complete personal protective equipment, including overall gown and protective boots and gloves. It is important to note that the lack of suitable and sufficient protective equipment, the lack of knowledge regarding the correct usage of equipment and the lack of pertinent understanding of the personnel regarding the benefits of using protective equipment exposes personnel to serious dangers. The hospital does not maintain a record/ register for medical waste disposal.

Temporary Storage: The place where the hospital waste is kept before transporting to the final disposal site is termed as a temporary waste storage area. This area must be well sanitised and secured in such a way that it should be accessible only to authorised persons (Prüss et al., 1999). Kotuba hospital has a well secured but poorly sanitised temporary storage area. The wastes are kept in this temporary storage area until it is time for off-site transport. The infectious and non-infectious wastes are kept in separate containers and are not mixed together in the hospital's own temporary storage area. On the whole, the hospital maintains three collections points for medical wastes.

Medical Waste Treatment: Waste treatment leads to a decrease in volume, weight, and risk of infectivity and organic compounds of the waste (Prüss et al., 1999). During the interview, it was indicated to the researcher that Kotuba hospital outsources its waste management function to a waste management company. Incineration is the main method for the treatment of medical waste especially infectious and sharp wastes for the hospital. Autoclaves are used for treating part of the wastes. 
Off-site Transport of Medical Waste: Offsite transport of the hospital waste is undertaken by a waste management company and waste is transported daily. Small pickups are mainly used by the waste management company for off-site transportation of waste. Johannessen et al (2000) recommend that transportation of medical waste on public roads must be carried out by trained staff in a dedicated vehicle with closed containers. However, the wastes are loaded directly into the pickup without putting them first into closed containers. Given the small size of the pickups, the wastes are usually heaped and they fall off on the roads during transportation. The hospital's staffs are not involved in this function and therefore there is no supervision from the hospital. There are instances were wastes that fall off the pick during loading at the hospital's premises are unattended to. This poses a serious health risk as well as a nuisance to workers and patients.

Final Disposal of Medical Waste: Diaz et al (2005) identified some of the more common treatment and disposal methods utilised in the management of infectious medical wastes in developing countries to include autoclaves and retorts; microwave disinfection systems; chemical disinfections; combustions (incineration); and disposal on land (dump site, controlled landfill, pits and sanitary landfill). The final disposal of the medical waste is done by the private waste management company. The main treatment method used in the final disposal of infectious waste is incineration. Wastes from hospitals are transported to an off-site area, which has been dedicated for this purpose. Non-infectious waste is disposed off using land disposal method. The final disposal site for medical wastes is accessible only by authorised persons. Recycling of the medical waste is not practiced in the hospital except white office paper and mixed office paper and the use of empty containers of antiseptics for the collection and temporary storage of sharps. The hospital during the time of the study did not have a subcommittee to monitor how the final disposal of the medical waste is done. Everything is left at the call of the waste management company.

It was also revealed during the interview that the hospital does not have a program in place in eliminating the use of mercury-containing products. There is also no programme in place to reduce, minimise the purchase and use of PVC (\#3) plastic packaging and containers.

Medical Staff: The waste management function at the hospital is under the general services department with a supervisor who reports to the Deputy Director of Administration. The general services department is also in charge of security, reprographics, typists, archives and messengers, transport, gardens, cleaning, pest control, lift operators, pneumatic tube exchange, telephone exchange, porters and mortuary. There is also a nurse in charge of medical waste at the ward level who reports to the head of infection control department, who is a professor. Staff in charge of the medical waste do not have any qualification in medical waste management. The supervisor has attended a short course on health care waste management, organised by Technology Services International. This was a two day course of 8 hours each day.

The interview indicated that training was not provided to doctors and other personnel about medical waste management and their potential hazards. Newly hired waste management staffs are not given any form of training. Staff members are also not given training on the health and environmental effects of infectious waste annually. The private waste management company workers who are responsible for the off-site transportation of medical waste to the final disposal site are not cautioned about the hazards associated with medical waste. The company's workers have not receive any formal training with regard to medical waste management, and are consequently unaware of the environmental health impacts of medical waste. Lack of proper training in the hospital poses serious risks to the personnel as far as the hazards of hospital waste is concerned. The process of collection, segregation and disposal of hospital waste are not performed according to recommended standards, hence patients, visitors, society and the entire environment are exposed to the dangers of such waste.

In developed countries, training programs and educational classes are instituted repeatedly for all personnel and the content of these programs are specifically designed for different personnel. In the USA, part 1910, 1030 are related to Occupational Health and Welfare (29 CFR part 1910, 1030 OSHA) and regulates the training needs for different personnel who are employed in centres where hospital waste production occurs (New York State, Department of Environmental Conservation, 1996).

Medical Waste Management Policies and Regulations: There is no clear policy and plan in place for managing medical waste at the Kotuba hospital. There is no definite policy or plan for purchasing the necessary equipment and for 
providing the facilities for the correct management of medical waste in the hospital. The hospital has a medical waste management guideline prepared by the head of infection control but this is not strictly followed. There are areas where medical waste management at the hospital is not properly done. For instance, there is no segregation of medical waste, particularly sharps. The hospital does not have a regular report about how medical waste management is practiced and the process of performing respective studies is also not reported. On the contrary, in developed countries, definite rules and regulations exist at the national, regional and hospital levels. For example, in the University Hospital of Freiburg, Germany, there are almost 36 rules at the national level, five rules at the regional level and 13 rules at hospital level resulting in a total of 54 rules for the correct management of hospital waste (Daschner, 2000). The interview however revealed that Kotuba hospital in the last three years has carried out a waste management audit. There are however no policies and guidelines regarding the recycling of medical waste products.

Problems of Medical Waste Management: During an interview with the head of infection control unit and the supervisor in charge of general services, it was revealed that the hospital currently has a number of problems in managing its medical waste. The main problems facing the hospital in terms of medical waste management include:

- Lack of necessary rules, regulations and instructions on the different aspects of collections and disposal of waste.

- Intermingling of hazardous wastes with domestic waste of the hospital sometimes.

- Failure to quantify the waste generated in reliable records.

- Lack of use of coloured bags thereby limiting the bags to only one colour for all waste.

- The absence of a dedicated waste manager. The supervisor in charge of general services has waste management as part of his job schedule.

- The absence of a committee responsible for monitoring medical waste management practices.

- Lack of education and training on medical waste management.

Conclusion and Recommendations: In the light of the above observations made during the research, a number of recommendations are made with the hope of improving the management of medical waste in hospitals in general and Kotuba hospital in particular. The following recommendations could enhance the operating efficiency of the hospitals with regards to medical waste management:
- It is important to measure and quantify the amount of medical waste generated in each unit of the hospital periodically to ascertain which unit or department generates the highest and lowest amount of wastes. This could have implications for resource allocation in managing medical waste.

- There is the need for proper segregation of infectious medical waste and non-infectious medical waste. The provision of plastic bags and strong plastic containers for infectious waste such as empty containers of antiseptics used in the hospital is necessary. Bags and containers for infectious waste should be marked with Biohazard symbol. A standardised system of red colour coded bags used for the segregation of risky waste should be used and rigidly followed. Imposition of segregation practices within the hospital will result in a clean waste stream which can be easily, safely and cost-effectively managed.

- The hospital should institute an efficient Sharps Management System, including proper equipment and containers at all sharps generating points, a secure accounting and collection system for transpoting the contaminated sharps for treatment and final disposal and the proper training of hospital staff on the handling and management of sharps.

- The hospital should institute regular training and education to all workers, from doctors to ward boys, laborers, rag pickers and also workers of the private waste management company. Proper training is necessary to develop awareness of health, safety and environment issues. It is important for workers to know and understand the potential risks associated with healthcare wastes, and the importance of consistent use of personal protection equipment.

- Medical waste should be transported in suitable dedicated wheeled leakproof containers. They should be clearly marked and regularly cleaned. The waste should be carried in a special purpose vehicle or in a special leak-proof, lidded container.

- Environmental health experts must be included in the infection control team in the hopital, as well as some waste management experts. This will improve the ability and effectiveness of the Infection Control team to carry out its operations.

- There must be a separate department for dealing with medical waste and another for domestic waste. This may increase the efficiency of medical waste management.

- $\quad$ The hospital should develop clear plans and policies for proper management and disposal of medical wastes. It is important to formulate a medical waste management policy separately from the hospital's waste management system. This should be 
done by a multidisciplinary team including environmental health experts.

- The hospital must set up a sub-committee to be responsible for medical waste management in the hospital. The sub-committee will be in charge of periodical reviewing and resolving medical waste management issues in the hospital. The committee should also monitor closely the activities of the private waste management company to ensure that they perform their duties as expected.

Medical waste must be separated from municipal waste, but in many parts of Africa it tends to be collected along with the rest of the waste stream. Poor management of medical waste has serious health implication to health workers, patients and the public. Also, due the toxi nature of medical waste, improper handling may lead to the destruction of natural environment and disturb the balance of ecosystems. This study examined the medical waste management practices in one major hospital in Southern Africa. From the results of the study, it is obvious that medical waste management is not practiced according to recommended standards. There are areas where medical waste management at the hospital is not properly done. It is imperative for significant investment in the proper management of medical waste in order to reduce the health risk it poses. The researcher hopes that this study will create awareness regarding the problem of medical waste management in hospitals and will generate interest for systematic control efforts for effective medical waste management.

Following from the findings of the study, it would be useful to also consider the following directions for future research: The medical waste management practices of public and private hospitals in Southern Africa; The health effects of medical waste disposal in Southern Africa;

\section{REFERENCES}

Askarian, M., Vakili, M.and Kabir, G. (2004), Results of a hospital waste survey in private hospitals in Fars province, Iran, Waste Management, 24, 347-352

Baveja, G., Muralidhar, S. Aggarwal, P. (2000), Hospital Waste Management - An Overview, Hospital Today, 5(9), 485-486.

Daschner, F. (2000), EU-Project: Reduction and Utilisation of Hospital Waste, with the Focus on Toxic and Infectious waste (LIFE 96 ENV/D/10). Final Report, Freiburg.

Department of Environmental Conservation, December 1996, New York State. Division of Solid and Hazardous Materials. Guidance for Regulated Medical waste Treatment, Storage, Containment, Transport and Disposal.

Diaz, L. F., Savage, G. M. and Eggerth, L. L. (2005), Alternatives for the Treatment and Disposal of Healthcare Wastes in Developing Countries, Waste Management, 25, 626-637.
Groundwork (2002), Eliminating the harmful Impacts of Heaath Care Waste and Incinerators in Southern African Communities, http://www.groundwork.org.za/HCW

Hardoy J. (1992), Environmental Problems in Third World Cities, Earthscan London: Publications

Johannessen, L.M., Dijkman, M., Bartone, C., Hanrahan, D., Boyer, G. and Chandra, C. (2000), Health Care Waste Management Guidance Note, Health Nutrition and Population Discussion Paper.

Kgathi, D.L, Bolanee, B. (2001), Instruments for Sustainable Solid Waste Management in Botswana, Waste Management Research, 19, 342-53.

Leonard, L. (2004), Health Care Waste in Southern Africa: A Civil Society Perspective.

Oweis, R., Mohamad, Al-Widyan and Ohood, Al-Limoon (2005), Medical Waste Management in Jordan: A Study at the King Hussien Medical Centre, Waste Management, 25, 622-625.

Patil, G. V. and Pokhrel, K. (2005), Biomedical Solid Waste Management in an Indian Hospital: A Case Study, Waste Management, 25, 592-599.

Prüss, A. Giroult, E. and Rushbrook, P. (1999), Safe Management of Wastes from Health-Care Activities, Handbook, World Health Organisation, Geneva.

Rao, S. K. M, Ranyal, R. K. and Sharm, V. R. (2004), Biomedical Waste Management: An Infrastructural Survey of Hospitals, MJAFI, 60, 379-382.

Silva, C. E., Hoppe, A. E., Ravanello, M. M. and Mello, N. (2005), Medical Waste Management in the South of Brazil, Waste Management, 25, 600 - 605.

Taru, P. and Kuvarega, A. T. (2005), Solid Medical Waste Management. The Case of Parirenyatwa Hospital, Zimbabwe, Revista Biomédica, 16, 153-158

WHO (1999), Safe Management of Wastes from Health Care Activities, World Health Organisation.

WHO (2005), Management of Solid Health-Care Waste at Primary Health-Care Centres, A Decision-Making Guide, World Health Organisation, Geneva.

Wong, K. V., Narasimham, R. Kasyap, R., Fu, J. (1994), Medical Waste Characterisation, Journal of Environmental Health, 57, 19-25. 